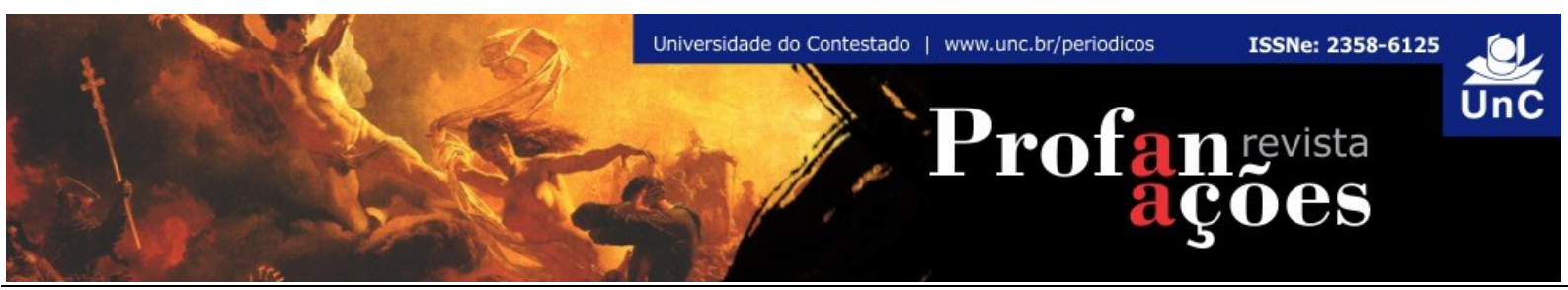

\title{
O ESTADO DE EXCEÇÃO NA HISTÓRIA A CONTRAPELO
}

Melissa Mendes de Novais ${ }^{1}$

\begin{abstract}
RESUMO
Este artigo procura delinear o paradigma do estado de exceção no pensamento de Giorgio Agamben, estabelecendo as devidas diferenciações em relação a forma como esse conceito é utilizado no debate público atual a fim que de que o paradigma agambeniano seja reconhecido em sua radicalidade. Para Agamben, o estado de exceção não diz respeito a uma categoria histórica identificável e nem se confunde com modelos estáticos ou legalmente prescritos, tais como a ditadura, o estado de defesa ou estado de sítio. Trata-se de uma criatura da tradição democráticoconstitucional que se diferencia tanto da estrita facticidade, quanto da juridicidade ou da lacuna. O que afinal é o estado de exceção agambeniano? É força de lei sem lei como vigência sem significado da lei, anulando a diferenciação entre Estado de Direito e estado de exceção.
\end{abstract}

Palavras-chave: Estado de exceção. Agamben. Estado de Direito.

\section{THE STATE OF EXCEPTION IN HISTORY AGAINST THE GRAIN}

\begin{abstract}
This article seeks to delineate the state of exception paradigm in Giorgio Agamben's thought, establishing the proper differences as to how this concept is used in the current public debate, so that the Agambenian paradigm is recognized in its radicality. For Agamben, the state of exception does not concern an identifiable historical category and is not confused with static or legally prescribed models such as dictatorship, state of defense or state of siege. It is a creature of the constitutionaldemocratic tradition that differs from both strict facticity and legality or disability. After all, what is the state of Agambenian exception? It is lawless force of law as meaningless force of law, nullifying the differentiation between rule of law and state of exception.
\end{abstract}

Keywords: Exception state. Agamben. Rule of law.

\footnotetext{
${ }^{1}$ Mestranda em Direito pela Universidade Federal de Santa Catarina (UFSC). Especialista em Direito Público pelas Faculdades Integradas Pitágoras (FIP-MOC). Bacharel em Direito pelas Faculdades Santo Agostinho (FADISA). Universidade Federal de Santa Catarina. Santa Catarina. Brasil. E-mail: melissamendes91@gmail.com
} 


\section{INTRODUÇÃO}

"A tradição dos oprimidos nos ensina que o 'estado de exceção' em que vivemos é na verdade a regra geral. Precisamos construir um conceito de história que corresponda a essa verdade" (BENJAMIN, 2005, p. 226).

Um conceito serve como instrumento para se lidar com a realidade e se referir a ela atribuindo-lhe certos sentidos. Se Agamben pretendia recorrer ao conceito de estado de exceção para fazer uma certa leitura da história pretendendo se livrar de conceitos desgastados e vazios como os de democracia e ditadura, por outro lado, o próprio conceito de estado de exceção parece ter perdido parte de seu potencial crítico, ou poiético, em função dos diversos e massificados usos desse conceito na esfera pública brasileira.

É compreensível que diante de confrontos institucionais/testes às instituições democráticas brasileiras e dos diversos conflitos políticos que envolveram o país nos últimos tempos o conceito agambeniano tenha sido utilizado de maneira apressada. O objetivo deste trabalho não é o de controlar o uso mais ou menos adequado do conceito de Agamben, mas, por se tratar de um conceito tão frequentemente utilizado e que suscita tantas defesas quanto críticas, de tentar delimitar e contribuir para a discussão sobre o estado de exceção apresentado por Agamben a fim de que tanto críticos quanto defensores cheguem, ao menos, a uma linguagem comum. Costumase designar o estado de exceção de forma tão caricata que serve de arma para os defensores mais apaixonados e como espantalho para o céticos e críticos de Agamben.

Se o conceito de estado de exceção é o mais adequado para lidar com a realidade brasileira atual é algo que deve ser discutido em outro momento. A pretensão deste trabalho é mais descritiva que prescritiva. Este artigo busca traçar um panorama geral da concepção de estado de exceção na filosofia de Giorgio Agamben. A radicalidade da proposta agambeniana serve ao reconhecimento de que as estruturas do Estado de direito se assentam sobre um vazio. Se Agamben tenta mostrar que Estado de direito e estado de exceção são indiscerníveis, isso não significa uma plena anomia, mas a específica anomia do Estado de direito. Se outra lei existe é sobre ela que importa pensar. 
Não é sobre o público e o privado, mas sobre o campo que se fala. Não é sobre o homem e o cidadão, mas sobre o homo sacer². Não é sobre o direito e a anomia, mas sobre a exceção. O fascínio atual pelo estudo do totalitarismo e dos seus portavozes, representado pelo resgate de autores de viés autoritário como Carl Schmitt para a leitura da realidade, aponta a obscura afinidade entre democracia e totalitarismo: a biopolítica (ou tanatopolítica) que as atravessa. Para além das suas irrevogáveis diferenças é aquilo que os aproxima que deve ser trazido à luz.

A fim de apresentar a concepção de estado de exceção em Agamben, o artigo está dividido em três tópicos. O primeiro tópico contextualiza onde o conceito de estado de exceção está situado na obra de Giorgio Agamben e em seguida, o estado de exceção é apresentado como uma perspectiva que procura vislumbrar não as luzes, mas a obscuridade e que acompanha a tradição dos oprimidos, razão pela qual o estado de exceção é a história a contrapelo do Estado de direito. O segundo tópico procura afastar do paradigma agambeniano do estado de exceção do que ele não é para, a partir daí, no último tópico, definir o que para Agamben constitui a teoria do estado de exceção.

\section{AGAMBEN E A LEITURA CONTEMPORÂNEA DA HISTÓRIA}

\subsection{PENSAR COM AGAMBEN}

Pensar o nosso tempo a partir de Agamben e com ele decorre dessa aposta no ser humano como ser sem obra, capaz de linguagem e, portanto, de história. $\mathrm{Na}$ sociedade do espetáculo em que vivemos, é justamente esse Comum (linguagem, potência, pensamento) que nos é expropriado ${ }^{3}$. O capital tornado imagem revela que

\footnotetext{
${ }^{2} \mathrm{O}$ homo sacer era uma figura do direito romano arcaico que designava aquele fora julgado pelo povo pelo cometimento de um delito e que, portanto, era considerado como homem sacro. Esse homem não poderia ser licitamente sacrificado, mas qualquer pessoa que o matasse não seria considerado homicida (AGAMBEN, 2010a).

${ }^{3}$ Para Hannah Arendt essa alienação do mundo decorre de uma particular compreensão de mundo que ela desenvolve a partir do estudo da situação dos refugiados e apátridas. Esses sujeitos desmundanizados perderam o contato com aquilo que se interpõe entre os homens separando-os e, simultaneamente, unindo-os. Eles são produto dos campos de concentração, enquanto fábricas de homens sem mundo. A destituição do "comum" e do "humano", isto é, do "estar entre homens" teve sua máxima representação na figura dos refugiados. Não é por acaso, que no contexto espetacular em que estamos inseridos, Agamben invoque como paradigmas políticos atuais o campo e o refugiado.
} 
o capitalismo "não estava voltado somente à expropriação da atividade produtiva, mas também e, sobretudo, à alienação da própria linguagem, da própria natureza linguística e comunicativa do homem" (AGAMBEN, 2013d, p. 79).

Giorgio Agamben nasceu em Roma em 1942 e se tornou um dos filósofos mais influentes da atualidade. Tratando de temas que envolvem desde estética à filosofia política, teologia, recorrendo a uma miríade de autores antigos, medievais, modernos e dialogando com diversas tradições ${ }^{4}$, o filósofo italiano nos apresenta uma filosofia complexa e ousada. Ele se desvencilha de uma função filosófica apaziguadora e põe o todo em questão a cada instante. Eis a radicalidade do projeto agambeniano, a crítica civilizacional do Ocidente.

A filosofia de Agamben é um convite ao pensamento, por isso não se deve esperar de suas análises o retorno ao paraíso, a restauração das promessas da modernidade ou um novo modelo. A decadência e a crise de conceitos fundamentais da tradição democrática têm fragilizado a compreensão e a crítica do nosso tempo. Num contexto em que categorias como política, soberania, Estado, povo, poder constituinte, etc. Não nos servem como elementos adequados sequer para uma análise descritiva da realidade, a revisão desses conceitos operacionais básicos da filosofia política, é um estágio necessário ${ }^{5}$. Agamben caminha a partir desse pressuposto, compreendendo que não é possível um debate profícuo recorrendo a elementos tais como soberania, quando, na centralidade em que ocupa a máquina governamental, seria mais conciso falar em governabilidade como o atual modelo político.

Dois momentos convergentes podem ser identificados nas produções bibliográficas do autor. O primeiro destaca-se pela relevância dos temas relacionados à estética e à linguística. O segundo, dá maior ênfase à filosofia política, "mas trazendo no bojo de tais discussões elementos de seu pensamento anunciados e refletidos na primeira fase" (ASSMANN; BAZZANELA, 2013, p. 25).

\footnotetext{
${ }^{4}$ A diversidade de influências desse autor se manifesta pelo peculiar diálogo entre Walter Benjamin, Heidegger, Michel Foucault, Hannah Arendt, Aristóteles, Deleuze, Carl Schmitt entre outros.

$5 \mathrm{O}$ projeto Homo Sacer apresenta uma leitura do poder no Ocidente que recorre a paradigmas genuinamente políticos: o bando como relação política originária, o campo como paradigma biopolítico e a vida nua como elemento político original que articula natureza e cultura, zoé e bíos. Isso porque, "os termos soberania, direito, nação, povo, democracia e vontade geral encobrem agora uma realidade que não tem mais nada a ver com aquilo que tais conceitos designavam e quem continua acriticamente servindo-se deles não sabe literalmente do que está falando" (AGAMBEN, 2015a, p. 101-102).
} 
Não se trata, por óbvio, de uma separação estanque. Desde seu primeiro livro publicado, O homem sem conteúdo (1970), cujo eixo fundamental é a crítica do paradigma estético, Agamben já avança na discussão política. Do mesmo modo, a dimensão da linguagem nunca foi abandonada pelo autor, a fratura entre a voz e a linguagem que liberta o homem do reino da necessidade e lhe investe na condição de um ser sem obra e, portanto, capaz de potência. Atravessa todo seu pensamento a formulação de uma ontologia da potência, que desative a matriz biopolítica do Ocidente ${ }^{6}$.

Em seu percurso teórico, destaca-se a tetralogia intitulada "Homo Sacer", situada nessa segunda fase de suas pesquisas. Agamben inaugura suas escavações arqueológicas em torno da origem da sacralidade da vida com o livro Homo Sacer, que aparece com o algarismo I em seu frontispício. As investigações estão dispostas da seguinte forma7:

-- HS I: Homo Sacer: o poder soberano e a vida nua (1995).

-- HS II, 1: Estado de exceção (2003);

-- HS II, 2: Stasis: la guerra civile come paradigma político (2015);

-- HS II, 3: O Sacramento da linguagem: arqueologia do juramento (2008);

-- HS II, 4: O Reino e a Glória: uma genealogia teológica da economia e do governo $^{8}$ (2007);

-- HS II, 5: Opus Dei: arqueologia do ofício (2012);

-- HS III: O que resta de Auschwitz: o arquivo e a testemunha (1998);

-- HS IV, 1: Altíssima Pobreza: regras monásticas e formas de vida (2011);

${ }^{6}$ Entre Foucault e Agamben se estabelece uma distinção, reconhecida por Agamben, em relação à biopolítica. Se para Foucault a biopolítica é um produto da modernidade, para Agamben, toda a política Ocidental é sempre biopolítica. Edgardo Castro, porém, afirma que, ao lado do paradigma teológico-político e do econômico-governamental, "é possível distinguir dois sentidos da biopolítica em Agamben, a biopolítica da soberania (cuja cronologia estende-se desde a Antiguidade até nossos dias) e a biopolítica da governamentalidade (a biopolítica moderna, cuja cronologia coincide com a que propõe Foucault)" (CASTRO, 2013, p. 137). O que caracteriza a "biopolítica da modernidade" é a "radicalização sem precedentes do estado de exceção" (AGAMBEN, 2010a p. 149), assim como a contínua necessidade de redefinição da vida e de seu valor ou desvalor, o que marca a decisiva conversão da biopolítica em tanatopolítica. Nesse sentido, a "novidade da biopolítica moderna é, na verdade, que o dado biológico seja, como tal, imediatamente biopolítico e vice-versa" (AGAMBEN, 2010a, p. 144).

7 As pesquisas não observam uma ordem cronológica sequencial, mas vão acompanhando os desdobramentos das próprias investigações. Cada texto é hermético e pode ser lido como um todo autônomo.

${ }^{8}$ Argumenta-se que a exata numeração de O reino e a glória é II.4 e não II.2 como consta na contracapa (CAVALLETTI, 2015). 
-- HS IV, 2: L'uso dei corpi (2014).

Assim é que Agamben se propõe a pensar a realidade e seu avesso. Ao protagonismo da vida nua no Ocidente, ele opõe a potência da vida que se traduz em forma-de-vida como vida política. O poder político que implica sempre separação e sacralização deve dar lugar à política como potência. Para Agamben, não é possível um retorno incólume ao Estado de direito, as apostas da modernidade devem ser abandonadas, assim como "a aposta de que tudo pode ser resolvido através do cumprimento da norma, e por isso abandonar também a aposta no 'estado de direito"' (ASSMANN, 2007, p. 14). O que resta é a tarefa de pensar um novo uso, para uma "comunidade que vem", na qual seja possível uma política alheia ao estatal e ao jurídico.

De um lado, o que se poderia identificar como a proposta ainda inconclusiva de Agamben em relação à exceção: a desativação do direito, a inoperosidade de uma comunidade que vem, a profanação do improfanável, a possibilidade de uma formade-vida sem qualquer relação com o direito, um novo uso, todas como formas diversas de se tratar de uma mesma questão: uma ação política exclusivamente destituinte. De outro lado, o diagnóstico estaria contido no reconhecimento de que a política no Ocidente se constrói por meio de uma exclusão inclusiva do ser vivente no espaço público de forma que o direito manteria uma necessária vinculação com a anomia que o constitui. Mais que isso, Agamben ainda desenvolve a tese de que essa estrutura teria finalmente atingido seu pleno desenvolvimento nos Estados contemporâneos, mesmo os ditos democráticos, por meio da "criação voluntária de um estado de emergência permanente" (AGAMBEN, 2011a, p. 13). Nesse sentido, o estado de exceção contempla uma das faces do diagnóstico de Agamben sobre os Estados contemporâneos.

\subsection{UMA HISTÓRIA A CONTRAPELO}

Em um ensaio de 2007, Agamben questiona: "De quem e do que somos contemporâneos? E, antes de tudo, o que significa ser contemporâneo?". No rastro de uma filosofia nietzscheniana do martelo, Agamben afirma a intempestividade do contemporâneo. Pertence ao seu tempo aquele que não coincide inteiramente com 
este, "mas exatamente por isso, exatamente através desse deslocamento e desse anacronismo, ele é capaz, mais do que outros, de perceber e apreender o seu tempo" (p. 58-59). Não é, porém, um nostálgico ${ }^{9}$, mas aquele que reconhece seu irrevogável pertencimento a seu momento histórico.

Agamben apresenta, então, uma segunda definição e ainda mais incisiva, "contemporâneo é aquele que mantém fixo o olhar no seu tempo, para nele perceber não as luzes, mas o escuro" (AGAMBEN, 2009, p. 62). Essa particular experiência do tempo presente, que desnuda as trevas que lhe envolvem e contempla a sua obscuridade, deixa antever a figura do estado de exceção como aquela que se apresenta numa história da tradição dos oprimidos. Uma tal abordagem "a contrapelo da história" desvenda os monumentos de barbárie da cultura posta sob os panos quentes de discursos de progresso manifestados de diversas formas (inclusive no interior do discurso da constitucionalização dos direitos, ou no desenvolvimentismo econômico), versões religiosas que não ousam dizer seu nome.

Walter Benjamin defende que a história seja escrita do ponto de vista dos vencidos, isto é, a partir da tradição dos oprimidos. Na sua sétima tese sobre o conceito de história, ele aponta que o método com o qual rompeu o materialismo histórico foi exatamente aquele da empatia, pois, com quem o historiador estabelece empatia senão com o vencedor?

Todos os que até hoje venceram participam do cortejo triunfal, em que os dominadores de hoje espezinham os corpos dos que estão prostrados no chão. Os despojos são carregados no cortejo, como de praxe. Esses despojos são o que chamamos bens culturais. O materialista histórico os contempla com distanciamento. Pois todos os bens culturais que ele vê têm uma origem sobre a qual ele não pode refletir sem horror. Devem sua existência não somente ao esforço dos grandes gênios que os criaram, como à corvéia anônima dos seus contemporâneos. Nunca houve um monumento da cultura que não fosse também um monumento da barbárie. E, assim como a cultura não é isenta de barbárie, não o é, tampouco, o processo de transmissão da cultura. Por isso, na medida do possível, o materialista histórico se desvia dela. Considera sua tarefa escovar a história a contrapelo (BENJAMIN, 2005, p. 225, grifo nosso).

\footnotetext{
$9 \mathrm{O}$ contemporâneo identifica o presente como arcairco. $\mathrm{O}$ arcaico é aquilo que remete à arké, à origem. "Mas a origem não está situada apenas num passado cronológico: ela é contemporânea ao devir histórico e não cessa de operar neste, como o embrião continua a agir nos tecidos do organismo maduro e a criança na vida psíquica do adulto" (AGAMBEN, 2009, p. 69). É por essa razão que a via de um acesso ao presente assume a forma de uma arqueologia. A contemporaneidade por excelência é o tempo messiânico, o "tempo-de-agora" no qual o todo é a todo momento posto em questão. Cada momento da história se apresenta como prefiguração do presente messiânico (AGAMBEN, 2009).
} 
A pobreza de experiência como perda do referencial simbólico impede que a própria história represente essa voz dos que se encontram sob os escombros da cultura. A emergência e a relevância que os discursos acerca da lei da anistia, justiça de transição, direito a memória e do aumento de comissões da verdade a fim de se poder falar a respeito de uma história dos vencidos é uma evidência da escassez de discursos alternativos e da pobreza da experiência da barbárie. Desenterrar os corpos representa uma luta pela superação de uma crise que, em grande medida, se reconhece como "crise da relação com o passado" (AGAMBEN, 2013b, p. 352).

A história da América Latina tão despojada e massacrada quanto silenciada se reproduziu em espaços inadmissíveis: na própria Europa. O espaço de exceção territorialmente delimitado nas colônias perdeu seus referenciais territoriais, produzindo vida matável indistintamente. O assombro com os episódios que alcançaram os baluartes da razão "não gera nenhum conhecimento, a não ser o conhecimento de que a concepção de história da qual emana semelhante assombro é insustentável" (BENJAMIN, 2005, p. 226).

Atender a esse apelo obscuro da nossa época é o que Agamben chama de ser contemporâneo. A proposta da investigação arqueológica do estado de exceção contribui para a compreensão da realidade que nos envolve, de forma que o olhar sobre o passado se apresenta como sombra de uma interrogação sobre o agora.

Reconhecendo a pertinência do diagnóstico benjaminiano, Agamben tenta responder ao significado de viver em um estado exceção e como, do ponto de vista do direito, se deu essa "profunda transformação que se havia produzido na constituição material, isto é, na vida política das assim chamadas democracias nas quais vivemos" (AGAMBEN, 2006). A ambiguidade constitutiva da ordem jurídica, a relação entre o direito e a anomia, norma e vida é articulada pelo estado de exceção. Assegura-se, assim, o funcionamento da máquina governamental, constituída pela "dúplice estrutura da ordem jurídico-política do Ocidente, que parece basear-se ao mesmo tempo num elemento normativo e jurídico em sentido restrito, e também num elemento anômico e extra-jurídico" (AGAMBEN, 2005, p. 8).

Em Estado de exceção, a relação entre direito e anomia mostra-se como constituinte do próprio direito, apontando essa natureza dúplice da ordem jurídica, em 
que fato e direito se tornam indistintos. O estado de exceção expõe essa configuração e mantêm unidas essas figuras contraditórias no bojo do sistema jurídico.

Assim, Agamben parte do diagnóstico de que a "cultura política do ocidente não se dá conta de haver perdido por inteiro os princípios que a fundam" (AGAMBEN, 2011a, p. 33) e se lança à busca da genealogia do estado de exceção enquanto constituinte da ordem jurídica.

A tese central é a de que o estado de exceção tende a deixar de ser uma medida excepcional e limitada para se tornar o paradigma de governo na política contemporânea, esfumando, assim, as fronteiras entre democracia e absolutismo. $\mathrm{O}$ que resta da política e do agir político nesse cenário é o que persiste como indagação (AGAMBEN, 2011a).

\section{O ESTADO DE EXCEÇÃO EM NEGATIVO}

Antes de tratar de seus elementos constitutivos, importa abordar o estado de exceção partindo do que ele não é e desde já desfazer eventuais equívocos que possam obscurecer a compreensão do conceito agambeniano de estado de exceção. Essas considerações devem servir para assegurar uma inteligibilidade mínima que impeça a divergência acerca do fenômeno de se fala. A opção pelo termo "estado de exceção" não é neutra, afinal "a terminologia é o momento propriamente poético do pensamento" (AGAMBEN, 2011a, p. 15) ou, ainda, o seu momento poiético.

\subsection{UMA CATEGORIA PARADIGMÁTICA}

Homo Sacer é o primeiro volume de uma série de investigações genealógicas sobre paradigmas teológicos, políticos e biopolíticos, que, para Agamben, têm exercido importante influência sobre o desenvolvimento e a ordem política global das sociedades ocidentais. Por essa razão é que essa primeira obra trará uma série de premissas que serão desenvolvidas nas obras posteriores (AGAMBEN, 2006). Segundo o autor, cuida-se da primeira parte de um livro maior que compreenderá um tipo de "arqueologia da biopolítica sob a forma de diversos estudos sobre a guerra civil, a origem teológica da oikonomia, o juramento e o conceito de vida (zoé)" (AGAMBEN, 2006, p. 131). 
O livro Estado de exceção integra essas investigações dando-lhe continuidade como o denuncia a identificação "Homo sacer, II, 1" presente em sua contracapa. Isso traz algumas implicações, a primeira delas é que o estado de exceção é concebido como o desenvolvimento de uma arqueologia do direito em larga medida tributária do método foucaultiano ${ }^{10}$. Portanto, não diz respeito a uma categoria histórica identificável. Não se trata de encontrar um momento histórico originário capaz de desvelar a verdadeira natureza da exceção ou a sua mais profunda e essencial configuração. Assim, muito embora as figuras do homo sacer, do mulçumano, do estado de exceção, do campo, etc. tenham uma existência histórica positiva, eles são "tratados en dichas investigaciones como paradigmas, cuya función era la de constituir y hacer inteligible la totalidad de un contexto histórico-problemático más vasto" (AGAMBEN, 2010d, p. 11).

Nesse ponto, o resgate do pressuposto metodológico de Agamben fornece importantes contribuições para a compreensão do estado de exceção. O que se pretende por meio dessas incursões paradigmáticas é identificar algumas figuras que funcionam como exemplos, ou seja, laboratórios que forneçam suporte para o entendimento de contextos mais amplos. Isso exige o tratamento da exceção na perspectiva da dinâmica na qual ela está implicada e na lógica que ela se configura sem um apego demasiado a forma de sua existência histórica. Nesse aspecto, Agamben menciona que a expressão 'plenos poderes' com que, às vezes, se caracteriza o estado de exceção, refere-se à ampliação dos poderes governamentais e, particularmente, à atribuição ao executivo do poder de promulgar decretos com força de lei" (AGAMBEN, 2011a, p. 17).

Uma interpretação literal do estado exceção não permitiria a sua leitura desde a perspectiva do Judiciário, na medida em que se defrontaria com o necessário agigantamento do executivo que aparece nos exemplos históricos tratados no livro. Mesmo nesse sentido, Agamben afirma que a "expressão 'plenos poderes define uma das possíveis modalidades de ação do poder executivo durante o estado de exceção, mas não coincide com ele" (AGAMBEN, 2011a. p. 17, grifo nosso).

\footnotetext{
10 Agamben herda o método arqueológico de Michel Foucault, mas se apropria dele de um modo particular. Em Sigantura Rerum, Agamben trata do conceito de paradigma, da teoria das assinaturas e de relação entre história e arqueologia (AGAMBEN, 2010d). A partir do paradigma, Agamben convida a refletir sobre a realidade desde uma perspectiva que transcende a dimensão cronológica, mas que tematiza modelos e exemplos.
} 
A proeminência da face executiva do poder político como um todo ${ }^{11}$ aponta para o fato de que ao invés de razão e norma o que há é contingência e exceção, ao invés de direito, anomia. O que está aqui posto é a percepção de que o direito é decisão, na medida em que aquilo que não é lei, mas tem força de lei, convive com a norma em suspensão. Uma jurisprudência autorreferente é um exemplo de como o estado de exceção pode se materializar concretamente para além da visão exclusiva do Poder Executivo.

\subsection{UMA TEORIA GERAL}

Outra relevante distinção diz respeito ao conceito de estado de exceção como uma teoria geral que não se confunde com modelos estáticos ou legalmente prescritos, tais como a ditadura, o estado de sítio ou o próprio estado de exceção. Investigar o modo de funcionamento da máquina jurídico-política, deve exceder a mera menção a um direito especial, tal como o direito da guerra. Seu desenvolvimento teórico atinge uma dimensão mais estrutural, que exige a retomada do conceito de Estado ou mesmo de direito, pois o estado de exceção "enquanto suspensão da própria ordem jurídica, define seu patamar ou seu conceito-limite" (AGAMBEN, 2011a, p. 15).

O filósofo italiano aponta a confusão feita por Schmitt entre ditadura e exceção como o que the impediu de resolver as aporias da teoria. Isso porque, "o estado de exceção não se define, segundo o modelo ditatorial, como uma plenitude de poderes, um estado pleromatico do direito, mas, sim, como um estado kenomatico, um vazio e uma interrupção do direito" (AGAMBEN, 2011a, p. 75). Assim, os Estados totalitários do século XX não devem ser compreendidos como uma ditadura, já que nem Hitler nem Mussolini tomaram o poder de forma ilegal, mas permitiram que a constituição vigorasse em suspensão. O paradigma que determinou tais governos

\footnotetext{
11 Se a crítica de Agamben se restringisse a esse aspecto a reação imediata a exceção seria a preservação ou o resgate da separação dos poderes numa perspectiva institucional, o que equivaleria a defesa da retomada da teoria liberal dos pesos e contrapesos. Não é a essa concepção - ainda refém do modelo liberal - que Agamben conduz, mas a uma crítica muito mais radical da tradição política ocidental que nos impele a indagação sobre o futuro das democracias de massa.
} 
foi sutilmente definido como 'Estado dual' - a constituição legal de uma segunda estrutura, amiúde não formalizada juridicamente, que podia existir ao lado da outra graças ao estado de exceção. O termo 'ditadura' é totalmente inadequado para explicar o ponto de vista jurídico de tais regimes, assim como, aliás, a estrita oposição democracia/ditadura é enganosa para uma análise dos paradigmas governamentais hoje dominantes (AGAMBEN, 2011a, p. 76).

O mais autêntico e obscuro paradigma genealógico do estado de exceção para Agamben seria o iustitium ${ }^{12}$ romano. O iustitium não podia ser compreendido pela referência à ditadura, mas tratava-se da interrupção e suspensão da própria ordem jurídica. Na medida em que não se trata de um estado de direito, mas de um estado sem direito, os atos cometidos nesse vazio escapam a toda determinação jurídica. Ele afirma que caso "se quisesse, a qualquer preço, dar um nome a uma ação realizada em condições de anomia, seria possível dizer que aquele que age durante o iustitium não executa nem transgride, mas inexecuta o direito" (AGAMBEN, 2011a, p. 78).

A referência ao estado de exceção permite a Agamben explorar os benefícios de trabalhar com um conceito-limite ${ }^{13}$. Eis que "Um dos paradoxos do estado de exceção quer que, nele, seja impossível distinguir a transgressão da lei e a sua execução" (AGAMBEN, 2010a, p. 62).

\subsection{UM PRODUTO DA TRADIÇÃO DEMOCRÁTICA}

A história do desenvolvimento do estado de exceção é sugestiva não só pelo seu desprendimento da situação de guerra, mas, sobretudo, por que "o estado de 12 Agamben dedica um capítulo para tratar do iustitium, um instituto do direito romano que significa
literalmente "interrupção, suspensão do direito" (AGAMBEN, 2011a, p. 68), isto é, não se suspendia
a mera administração da justiça, mas o direito como um todo para o enfrentamento do tumultus:
"Quando tinha not́cia de alguma situação que punha em perigo a República, o Senado emitia um
senatus consultum ultimum por meio do qual pedia aos cônsules (ou a seus substitutos em Roma,
interrex ou pró-cônsules) e, em alguns casos, também aos pretores e aos tribunos da plebe e, no
limite, a cada cidadão, que tomassem qualquer medida considerada necessária para a salvação do
Estado [...]. Esse senatus-consulto tinha por base um decreto que declarava o tumultus (isto é, a
situação de emergência em Roma, provocada por uma guerra externa, uma insurreição ou uma guerra
civil) e dava lugar, habitualmente, à proclamação de um iustitium" (AGAMBEN, 2011a, p. 106).
13 Schmitt afirma que "O conceito-limite não é um conceito confuso, como na feia terminologia da
literatura popular, mas um conceito da esfera extrema; isso quer dizer que sua definição não se
encaixa num caso normal, mas sim num caso limite. O fato de se entender o Estado de exceção como
um conceito genérico da doutrina de Estado, e não como qualquer situação emergencial ou Estado
de sítio [...]" (SCHMITT, 1996, p. 88). 
exceção moderno é uma criação da tradição democrático-revolucionária e não da tradição absolutista" (AGAMBEN, 2011a, p. 16, grifo nosso).

Importa considerar que não foi o nazismo que criou os campos de concentração, mas eles foram frutos da lei marcial e do estado de exceção proclamados na vigência de governos social-democráticos. As medidas protetivas destinadas a preservar a segurança do Estado e que autorizavam o internamento foram tomadas no âmbito do estado de sítio.

Mais uma vez, o que se evidencia é a escusa continuidade entre democracia e totalitarismo.

\subsection{UMA DESLOCALIZAÇÃO}

O estado de exceção transcende a oposição topográfica (dentro/fora). "Estarfora e, ao mesmo tempo, pertencer: tal é a estrutura topológica do estado de exceção" (AGAMBEN, 2011a, p. 57). Não é nem fato, como o supõe a teoria da necessidade, e nem direito. Ele diz respeito à suspensão total ou parcial da própria ordem jurídica de modo que não lhe é nem interior, nem exterior,

\footnotetext{
o problema de sua definição diz respeito a um patamar, ou a uma zona de indiferença em que dentro e fora não se excluem mas se indeterminam [...]. Em todo caso, a compreensão do problema do estado de exceção pressupõe uma correta determinação de sua localização (ou de sua deslocalização) (AGAMBEN, 2011a, p. 39).
}

Nessa linha, é um equívoco considerar o estado de exceção como uma esfera contra a qual luta o Estado de direito. A exceção é aquilo que se mantém não em oposição, mas em complementariedade com o direito. A anomia funda o direito e com ele mantém uma necessária relação.

Outra delimitação negativa encontra-se na tese da necessidade. O estado de exceção não é uma questão de fato e de domínio de um estado de necessidade como o faz grande parte da teoria do direito público. A "contiguidade essencial entre estado de exceção e soberania" (AGAMBEN, 2011a, p. 11) já tinha sido identificada por Schmitt, mas é ainda em larga medida negada como um "genuíno problema jurídico", perdendo-se nas malhas incertas do político e do jurídico. Para Agamben, "É essa terra de ninguém entre o direito público e o fato político e entre a ordem jurídica e a 
vida" que se insere a sua pesquisa (AGAMBEN, 2011a, p 12), abrindo, talvez, o espaço para se responder à pergunta: "o que significa agir politicamente?" (AGAMBEN, 2011a, p. 12).

Para a tradição jurídica que reconhece a necessidade como o fundamento do estado de exceção, o adágio latino necessitas legem non habet (a necessidade não tem lei) permite que o juízo sobre a existência do estado de necessidade confira legitimidade ao estado de exceção. Esse brocardo deve ser compreendido "em dois sentidos opostos: 'a necessidade não reconhece nenhuma lei' e 'a necessidade cria sua própria lei"” (AGAMBEN, 2011a, p. 40).

A teoria da necessidade esteve sempre associada ao desaparecimento da obrigatoriedade, ao poder de tronar lícito o ilícito, de forma que a teoria da necessidade coincide com a teoria da exceção, pois a "necessidade não é fonte de lei e tampouco suspende, em sentido próprio, a lei; ela se limita a subtrair um caso particular da aplicação literal da norma" (AGAMBEN, 2011a, p. 41).

Essa situação se altera com os modernos que passam a assegurar a teoria da necessidade uma relação mais próxima com a ordem jurídica a ponto de, com Santi Romano, assumir a radicalidade de identificar a necessidade como o mais originário fundamento da lei.

o estado de exceção, enquanto figura da necessidade, apresenta-se pois ao lado da revolução e da instauração de fato de um ordenamento constitucional - como uma medida "ilegal", mas perfeitamente "jurídica e constitucional", que se concretiza na criação de novas normas (ou de uma nova ordem jurídica) (AGAMBEN, 2011a, p. 44).

Para Santi Romano, a fonte do direito é a necessidade e, mesmo que a lei seja a mais perfeita manifestação da norma jurídica, não coincide com ela. Assim, uma situação que decorra da necessidade, ainda que se apresente como ilegal do ponto de vista do Estado, não é antijurídica. Isso porque o direito, para ele, é determinado pelo ser e não pelo dever ser (ROMANO, 2008). Mas a aporia identificada por Agamben

contra a qual fracassa, em última instância, toda a teoria do estado de necessidade, diz respeito à própria natureza da necessidade, que os autores continuam, mais ou menos inconscientemente, a pensar como uma situação objetiva (AGAMBEN, 2011a, p. 46). 
Daí o mérito de Schmitt de reconhecer que, no limite, o direito é decisão. A discussão em torno do conceito de necessidade e seu significado político controverso pode ser compreendido a partir da afirmação de Schmitt:

\begin{abstract}
Em geral, não se briga por causa de um conceito, pelo menos não na história da soberania. Briga-se por causa da sua aplicação concreta, e isso significa brigar para saber quem toma as decisões em caso de conflito, para saber no que se constitui o interesse público ou estatal, a segurança e a ordem públicas, le salut public etc. [...]. Não se pode determinar com clareza precisa quando ocorre um caso emergencial, como também não se pode enumerar o que pode ser feito nesses casos, quando se trata realmente de um caso emergencial extremo que deva ser eliminado [...]; assim se evidenciará claramente quem é o soberano. Ele não só decide sobre a existência do Estado emergencial extremo, mas também sobre o que deve ser feito para eliminá-lo (SCHMITT, 1996, p. 88).
\end{abstract}

Nesse sentido, a necessidade muito antes de uma pretensa existência objetiva é fundamentalmente decisão. Para Schmitt, nem a norma e nem o fato são determinantes e a decisão é que se configuraria como um elemento puro, já que, encarada "normativamente, a decisão nasceu do nada" (SCHMITT, 1996, p. 106) e partindo do fato é central não existirem decisões meramente declaratórias. A objetividade é o limite no qual esbarra a teoria da necessidade. Schmitt, porém, mostra a sua verdadeira face e mostra o seu fundamento mais profundo, a decisão pura.

Agamben ainda assevera que "não só a necessidade se reduz, em última instância, a uma decisão, como também aquilo sobre o que ela decide é, na verdade, algo indecidível de fato e de direito" (AGAMBEN, 2011a, p. 47). Assim, para Agamben,

são falsas todas aquelas doutrinas que tentam vincular diretamente o estado de exceção ao direito, o que se dá com a teoria da necessidade como fonte jurídica originaria, e com a que vê no estado de exceção o exercício de um direito do Estado à própria defesa ou a restauração de um originário estado pleromático do direito (os "plenos poderes") (AGAMBEN, 2011a, p. 78-79).

O estado de exceção também não é o exercício de um direito ou uma configuração específica de direito que se amolde à necessidade, mas uma ausência de direito. Nesse vértice, é possível identificar a perda da distinção entre o público e o privado. No vazio de direito que a exceção expõe não há mais como distinguir direita e esquerda, público e privado e as tradicionais categorias políticas perdem a sua inteligibilidade. 
Isso já está apresentado pelo iustitium, na medida em que ele "parece questionar a própria consistência do espaço público; porém, de modo inverso, a do espaço privado também é imediatamente neutralizada" (AGAMBEN, 2011a, p. 76). No âmbito de uma economia autorreferencial instaurada pela exceção a única lógica que subsiste é a lógica econômica. Afinal, a exceção refere-se a um processo no qual o impolítico (vida nua) se politiza e o político se "economiciza", de sorte que a economia política é erigida como referência de toda a comunidade política, transformada numa grande oikos.

\subsection{PERTENCIMENTO AO ÂMBITO DO DIREITO CONSTITUCIONAL}

A teoria do estado de exceção pertence ao direito constitucional e não ao direito penal. Agamben, tomando como ponto de análise o iustitium, mostra que a ordem jurídica como um todo é posta em questão durante o estado de exceção. Este se apresenta como uma forma de legítima defesa do Estado, sendo que não apenas uma parcela do ordenamento, mas todo o direito é aglutinado pela excepcionalidade que o funda.

A existência de um duplo nível de legalidade jurídico-penal ${ }^{14}$, como marca do delito político não pode, nesse sentido, constituir senão um dos desdobramentos da exceção, mas não compreende a amplitude que ela envolve. Segundo Agamben, na exceção é impossível distinguir entre o irmão e o inimigo e a guerra civil tende a coincidir com a guerra global que toma a forma do terrorismo, não apenas do terrorismo que confronta o Estado, mas também o promovido pelo próprio Estado (AGAMBEN, 2015b). Agamben demonstra a aproximação do estado de exceção com a guerra civil, a insurreição e a resistência:

O totalitarismo moderno pode ser definido, nesse sentido, como a instauração, por meio do estado de exceção, de uma guerra civil legal que permite a eliminação física não só dos adversários políticos, mas também de categorias inteiras de cidadãos que, por qualquer razão, pareçam não

\footnotetext{
${ }^{14} \mathrm{~A}$ ideia de um duplo nível de legalidade foi formulada por Mario Sbriccoli e desenvolvida por Massimo Meccareli, que destaca a "incompatibilidade entre o horizonte da legalidade e o direito penal político" (MECCARELLI, 2009, p. 1). Esse duplo registro de legalidade refere-se às normas que se excepcionam à lei penal ordinária numa lógica mais sistemática que emergencial a fim de que o Estado se defenda do inimigo dito público (MECCARELLI, 2009). Nesse sentido, há uma legislação penal ordinária que convive com as excepcionais medidas tomadas em face do inimigo e do terrorista.
} 
integráveis ao sistema político. Desde então, a criação voluntária de um estado de emergência permanente (ainda que, eventualmente, não declarado no sentido técnico) tornou-se uma das práticas essenciais dos Estados contemporâneos, inclusive dos chamados democráticos (AGAMBEN, 2011a, p. 13).

Não há, pois, um duplo registro de legalidade na medida em que os limites entre a regra e a exceção já não podem mais ser traçados com precisão. $\mathrm{O}$ inimigo que ameaça de fora o Estado não pode ser definido, pois já não há dentro e fora e todos tornam-se virtualmente homines sacri.

\subsection{LACUNA FICTIICIA}

O estado de exceção não se confunde com as lacunas do direito. Não se refere à ausência de normas para regular uma situação de fato que o juiz deve corrigir, por meio do recurso a expedientes previstos pelo direito positivo como a analogia, os costumes e os princípios gerais do direito.

A lacuna que se abre pela exceção é fictícia e decorre da separação entre a norma e a sua aplicação. Enquanto a lacuna diz respeito a "carência no texto legislativo" (AGAMBEN, 2011a, p. 48), a suspensão do direito possibilitada pela exceção concerne a carência de normalidade do fato. Afinal, o estado de exceção é a figura que se estabelece quando a normalidade está comprometida. Se a norma pressupõe normalidade, a exceção abre o vazio na ordem jurídica e permite que medidas sejam adotadas para retomar a situação de normalidade, na qual o direito torna-se aplicável. Por isso, a "lacuna não é interna à lei, mas diz respeito à sua relação com a realidade, à possibilidade mesma de sua aplicação" (AGAMBEN, 2011a, p. 48).

Trata-se, pois, de um vazio que se produz, uma anomia induzida. Mas quando a anomia deságua para além das fronteiras do caso excepcional e inunda o império do direito, o totalitarismo mostra a sua face. A fim de que a democracia seja preservada, medidas antidemocráticas são adotadas. Esse fenômeno paradoxal é representado pelo caso nazista: assim que o poder Ihe foi entregue, Hitler suspendeu - pela promulgação de um decreto nunca revogado - os artigos referentes às liberdades individuais na Constituição Alemã, instituindo um estado de exceção que durou doze anos: o Terceiro Reich (AGAMBEN, 2011a). 


\title{
4 O ESTADO DE EXCEÇÃO COMO MÁQUINA JURÍDICO-POLÍTICA
}

Desembaraçando de todos os particularismos que mais servem a uma investigação histórica do que filosófica, o que resta de elemento constitutivo do estado de exceção, mais que a indefinição entre os poderes do Estado, é a força de lei que se traduz por uma lei que vige, mas não significa e pela aplicação sem vigência. Ambas afirmando um núcleo de suspensão da ordem jurídica para assegurar a sua existência. É uma lacuna fictícia que se abre no campo do direito público "com o objetivo de salvaguardar a existência da norma e sua aplicabilidade à situação normal" (AGAMBEN, 2011a, p. 48).

A força de lei pode ser vislumbrada a partir da distinção apresentada por Schmitt entre normas de direito e normas realização do direito na caraterização da ditadura comissária. Isso porque, o estado de exceção radicaliza a separação entre a norma e sua aplicação.

\begin{abstract}
Ele define um estado da lei em que, de um lado, a norma está em vigor, mas não se aplica (não tem 'força') e em que, de outro lado, atos que não tem valor de lei adquirem sua 'força'. No caso extremo, pois, a 'força-de-lei' flutua como um elemento indeterminado [...] O estado de exceção é um espaço anômico onde o que está em jogo é uma Força-de-lei sem lei (que deveria, portanto, ser escrita: força-de-lei. (AGAMBEN, 2011a, p. 61).
\end{abstract}

O conceito "força-de-lei" representa exatamente essa separação entre lei em sentido formal e a aplicação da lei. Esse conceito autoriza que atos que não sejam lei adquiram sua força. Assim, mais que a confusão entre os poderes, é o desprendimento da "força-de-lei" da lei e que flutua para ser reivindicada seja pela autoridade estatal, seja por forças revolucionárias. O que resta, quando o estado de exceção se torna a regra é a pura "força-de-lei" que manifesta o não-lugar da exceção:

como se a suspensão da lei liberasse uma força ou um elemento místico, uma espécie de mana jurídico [...], de que tanto o poder quanto seus adversários, tanto o poder constituído quanto o poder constituinte tentam apropriar-se. A força-de-lei separada da lei, o imperium flutuante, a vigência sem aplicação e, de modo mais geral, a ideia de uma espécie de "grau zero" da lei, são algumas das tantas ficções por meio das quais o direito tenta incluir em si sua própria ausência e apropriar-se do estado de exceção ou, no mínimo, assegurar-se uma relação com ele (AGAMBEN, 2011a, p. 79-80). 
De outro lado, a vigência sem significado da lei ou a lei que vige como simples forma é representada pela suspensão da ordem jurídica. Agamben aponta as dificuldades das pesquisas nesse campo, já que as pesquisas de Hannah Arendt sobre a condição humana não se referiram diretamente ao fenômeno do totalitarismo ${ }^{15}$ e Foucault não avançou nos estudos da biopolítica para chegar até sua máxima expressão, o campo de concentração.

A relação de bando, como estrutura da arché, não apenas na tradição jurídicopolítica, mas também na ontologia não pode ser ignorada. A máquina jurídico-política do Ocidente em sua articulação entre lei e anomia, autoritas e potestas, é operado pelo estado de exceção. Decisivo, porém, é o seu desenvolvimento moderno, "quando tendem a coincidir numa só pessoa, quando o estado de exceção em que eles se ligam e de indeterminam torna-se a regra, então o sistema jurídico-político transformase em uma máquina letal" (AGAMBEN, 2011a, p. 131)

Agamben retoma a tese schmittiana do soberano como aquele que decide sobre o estado de exceção para destacar o problema genuinamente jurídico que lhe envolve, não se tratando de uma mera questão de fato ou pertencente ao campo do estado de necessidade.

O filósofo italiano destaca o processo de transformação do papel do Parlamento nas democracias por meio da atribuição de plenos poderes ao Executivo, não apenas de forma excepcional, mas sistemática. Esse processo, que teria passado a assumir o estatuto de técnica de governo por meio da necessidade e urgência tornadas constantes, delega ao Executivo um poder legislativo que teria sido progressivamente sendo destituído do parlamento. A atuação do Parlamento como mero ratificador dos decretos executivos com força de lei, teria se tornado comum, evidenciando que "uma das características essenciais do estado de exceção - a abolição provisória da distinção entre poder legislativo, executivo e judiciário - mostra aqui, sua tendência a transformar-se em prática duradoura de governo" (AGAMBEN, 2011a, p. 19).

As teses fundamentais da doutrina do estado de exceção são apresentadas por Agamben conforme desenvolvido por Schmitt nos livros "A ditadura" de 1921 e "Teologia política" de 1922, cuja relação deve ser compreendida como a tentativa de

\footnotetext{
${ }^{15}$ Essa não é uma leitura dominante acerca da Condição Humana de Hannah Arendt. Celso Lafer, no posfácio à $10^{\mathrm{a}}$ edição, afirma a continuidade das obras As origens do totalitarismo e $A$ condição humana.
} 
inscrição do estado de exceção no direito. Em Teologia política, o problema da exceção se apresenta como o problema da soberania. No primeiro livro, por sua vez, o estado de exceção aparece sob a forma da ditadura, a partir da qual "distinguem-se a 'ditadura comissária, que visa a defender ou a restaurar a constituição vigente, e a 'ditadura soberana', na qual, como figura da exceção, ela alcança, por assim dizer, sua massa crítica ou seu ponto de fusão" (AGAMBEN, 2011a, p. 53). A ditadura comissária ou constitucional é temporária e é concebida com um meio para assegurar a ordem constitucional. Por seu turno, a ditadura soberana ou inconstitucional é permanente, vez que se revela com um fim em si mesma.

A distinção schmittiana entre ditadura comissária e ditadura soberana não suprime o "círculo vicioso segundo qual as medidas excepcionais, que se justificam como sendo para a defesa da constituição democrática, são aquelas que levam a sua ruína" (AGAMBEN, 2011a, p. 20).

Analisando o tratamento de Schmitt e Rossiter acerca do estado de exceção, Agamben identifica o estado de exceção com a ditadura constitucional e o problema de sua proximidade da ditadura soberana. A diferença que Schmitt já teria identificado, somente de grau e não de espécie, afirma o temor do próprio Rossiter de que essas práticas temporárias se tornem regra. $\mathrm{O}$

fim da República de Weimar mostra, ao contrário e de modo claro, que uma 'democracia protegida' não é uma democracia e que o paradigma da ditadura constitucional funciona sobretudo como uma fase de transição que leva fatalmente a instauração de um regime totalitário (AGAMBEN, 2011a, p. 29).

Determinante é que a indução à emergência e à exceção transcendeu o argumento estritamente bélico e assumiu cada vez mais uma feição econômica, certificando a passagem da guerra à economia. A Primeira Guerra mundial concebida como um estado de exceção permanente continua presente, mas transita para a esfera da economia. Nesse sentido, "é significativo que a emergência militar então desse lugar à emergência econômica por meio de uma assimilação implícita entre guerra e economia" (AGAMBEN, 2011a, p. 26). E assim,

sob a pressão do paradigma do estado de exceção, é toda a vida políticoconstitucional das sociedades ocidentais que, progressivamente, começa a assumir uma forma que, talvez, só hoje tenha atingido seu pleno desenvolvimento (AGAMBEN, 2011a, p. 27). 
A abertura e suspensão do direito é em grande medida determinada pelo discurso da segurança, revelando a tendência "em ato em todas as democracias ocidentais, a declaração do estado de exceção é progressivamente substituída por uma generalização sem precedentes do paradigma da segurança como técnica normal de governo" (AGAMBEN, 2011a, p. 27-28).

A história do artigo 48 da Constituição de Weimar é um grande exemplo, já que em várias ocasiões "o governo usou o artigo 48 para enfrentar a queda do marco, confirmando a tendência moderna de fazer coincidir emergência político-militar e crise econômica" (AGAMBEN, 2011a, p. 29).

Se anteriormente era a salvaguarda da segurança e da ordem pública que justificavam que os direitos fundamentais fossem suspensos, o desenvolvimento do estado de exceção passa a estar fundamentado na salvaguarda da própria Constituição, isto é, a suspensão da Constituição para a sua própria garantia. A teoria do estado de exceção no plano democrático esteve amparada ou no texto da própria constituição, ou num pretenso direito de necessidade, ou, ainda "sobre uma lacuna do direito que deve ser preenchida por disposições excepcionais [o que] mostra que a teoria do estado de exceção não é de modo algum patrimônio exclusivo da tradição antidemocrática" (AGAMBEN, 2011a, p. 30).

A Primeira Guerra teria dado início "a generalização dos dispositivos governamentais de exceção" (AGAMBEN, 2011a, p. 33). Mas a transição da exceção bélica para a emergência econômica se deu por meio do recurso à emergência seja no período da grande depressão nos EUA, seja em relação a queda do marco alemão, com o uso do linguajar da guerra. $O$ paralelismo entre a emergência militar e a emergência econômica caracteriza a política no século XX e essa transição foi autorizada pelo vocabulário da crise.

Para Agamben, a tradição jurídica se divide entre aqueles que "procuram inserir o estado de exceção no âmbito do ordenamento jurídico e aqueles que o consideram exterior a esse ordenamento" (AGAMBEN, 2011a, p. 38) ${ }^{16}$. Os que o consideram pertencente à ordem jurídica assim o fazem por compreender a necessidade como

\footnotetext{
${ }^{16}$ Agamben mostra que embora do ponto de vista formal o estado de exceção exista em todos os ordenamentos, há uma dualidade nas Constituições no que reputa a previsão ou não do estado de exceção. Para Schmitt, trata-se de uma pretensão inócua regulamentar o que necessariamente lhe escapa.
} 
fonte autônoma do direito, ou por o compreenderem como uma espécie de direito subjetivo, como parte do direito do estado à autoconservação. Outros consideram o estado de exceção como exterior ao direito, já que a necessidade no qual se funda é extrajurídica.

Agamben parte do debate entre Benjamin e Schmitt, iniciado com a publicação do ensaio benjaminiano "crítica da violência: crítica do poder", no qual Benjamin pretende invocar uma violência fora do direito, muito próxima a ideia de uma greve geral soreliana. É a figura de uma terceira violência, que rompesse com a dialética entre violência instituidora e violência mantenedora do direito, que Benjamin remete denominando-a de violência pura, ou divina. Trata-se de uma autêntica violência revolucionária, que não se presta a instituir ou conservar, mas depor o direito.

Schmitt responde num sentido diverso, ele tenta inscrever a exceção no direito através da figura da decisão soberana sobre a exceção. O que Benjamin faz é justamente mostrar que a separação entre o poder soberano e o seu exercício impede que o soberano decida e à impossibilidade de se distinguir norma e exceção só resta a violência, ou, a força de lei.

o que é igualmente essencial para a ordem jurídica é que essa zona [...] coincide com uma figura extrema e espectral do direito, em que ele se divide em uma pura vigência sem aplicação (a forma de lei) e em uma aplicação sem vigência: a força de lei (AGAMBEN, 2011a, p. 93).

O que fica exposto, assim, é a secreta solidariedade entre anomia e direito ${ }^{17}$, o fato de que é a força e não a norma o seu fundamento mais íntimo.

\begin{abstract}
É como se o universo do direito [...] se apresentasse, em última instância, como um campo de forças percorrido por duas tensões conjugadas e opostas: uma que vai da norma a anomia e a outra que, da anomia, leva a lei e a regra. Daqui resulta um duplo paradigma que marca o campo do direito com uma ambiguidade essencial: de um lado, uma tendência normativa em sentido estrito, que visa a cristalizar-se num sistema rígido de normas cuja conexão com a vida é, porém, problemática, senão impossível (o estado perfeito de direito, em que tudo é regulado por normas); de outro lado, uma tendência anômica que desemboca no estado de exceção ou na ideia do soberano como lei viva, em que uma força de lei privada de norma age como pura inclusão da vida (AGAMBEN, 2011a, p. 110-111).
\end{abstract}

\footnotetext{
17 Agamben argumenta que "Esse espaço vazio de direito parece ser, sob alguns aspectos, tão essencial à ordem jurídica que esta deve buscar, por todos os meios, assegurar uma relação com ele, como se, para se fundar, ela devesse manter-se necessariamente em relação com uma anomia" (AGAMBEN, 2011a, p. 79).
} 
O célebre artigo $48, \S^{\circ}$ da Constituição do Reich alemão de 11 de agosto de 1919 (Constituição de Weimar) tornou-se emblemático, já que desnuda o paradoxo de sua fundamentação: pela salvaguarda da constituição esta se vê suspensa.

\begin{abstract}
O presidente do Reich pode, caso a segurança pública e a ordem sejam gravemente perturbadas ou ameaçadas, tomar as decisões necessárias para o restabelecimento da segurança pública, se necessário com o auxílio das forças armadas. Com este fim pode provisoriamente suspender (ausser Kraft setzen) os direitos fundamentais contidos nos artigos 114, 115, 117, 118, 123, 124 e 153 (apud AGAMBEN, 2011a, p.174).
\end{abstract}

A confusão efetuada não apenas pela teoria, mas pela prática política do Ocidente, no sentido que fazer coincidir auctoritas e potestas na figura da soberania foi percebida por Carl Schmitt. No âmbito do direito privado, a autorictas deriva de augeo e de autor, referindo-se aquilo que não apenas aperfeiçoa, mas dá origem a um ato, tal como a auctoritas do tutor que confere validade jurídica ao ato do incapaz. Trata-se justamente daquela "força" que lança o ato no mundo jurídico atribuindo-Ihe validade.

A auctoritas pertence a tradição biopolítica e a potestas a jurídica. Na esfera do direito público, a auctoritas representava a prorrogativa do Senado romano de ratificar as decisões populares. Apresenta-se como o outro sujeito, isto é, uma terceira instância que condiciona a juridicidade, pois a "validade jurídica não é um caráter originário das ações humanas, mas deve ser comunicada a elas por meio de um 'poder que confere legitimidade"' (AGAMBEN, 2011a, p. 121).

A potestas, por sua vez, concerne ao poder jurídico pertencente aos magistrados e ao povo. "Auctoritas e potestas são claramente distintas e, entretanto, formam juntas um sistema binário" (AGAMBEN, 2011a, p. 120). A auctoritas aparece como o poder que confere legitimidade, ela "parece agir como uma força que suspende a potestas onde ela agia e a reativa onde ela não estava mais em vigor. É um poder que suspende e reativa o direito, mas não tem vigência formal como direito" (AGAMBEN, 2011a, p. 121). O que Agamben apresenta como conclusão provisória é que

O sistema jurídico do Ocidente apresenta-se como uma estrutura dupla formada por dois elementos heterogêneos e, no entanto, coordenados: um elemento normativo em sentido estrito - que podemos inscrever aqui, por comodidade, sob a rubrica de potestas - e um elemento anômico e 
metajurídico - que podemos designar pelo nome de auctoritas (AGAMBEN, 2011a, p. 130).

A máquina jurídico-política, compõe-se dessa dupla polaridade que se articula por meio da exceção que mantém indefinidos o direito e a anomia, o jurídico e o biopolítico, a potestas e a auctoritas, vigência da lei e força de lei, poder constituído e poder constituinte. A exceção que ocupa o centro da máquina é vazio, mas tão eficaz quanto fictício e o destino desse processo é a guerra civil mundial.

Superadas essas questões, emerge a tese central de que o fenômeno do estado de exceção não pode ser devidamente compreendido senão pela sua identificação como paradigma ou técnica de governo, sendo o governo compreendido como "modo de funcionamento do aparato biopolítico do nosso tempo" (AGAMBEN, 2014a, p. 24).

A teoria do estado de exceção não é um objetivo em si, mas deve se inscrever no contexto das tecnologias de governo (AGAMBEN, 2014a). A advertência é de que exceção tende a se tornar uma prática normalizada em função do clima generalizado de insegurança, garantindo a permanência de um fenômeno transitório. Eis o ápice da crise política.

\section{CONSIDERAÇÕES FINAIS}

Pensar, a partir de e com Agamben, a realidade jurídico-política das democracias ocidentais que teriam pretensamente superado os totalitarismos e sido postas a salvo de um retorno ao autoritarismo se mostra tanto mais necessário quanto complexo. Isso porque, no âmbito de uma urgência desejada que corrói elementos basilares do Estado de direito, não se pode tomar a devida distância que exige uma pesquisa mais consciente de todas as facetas da realidade que merecem atenção e corre-se, pois, todos os riscos de um trabalho que se encontra embebido na realidade investigada, presenciando o curso errático dos movimentos que se presta a questionar.

O estado de exceção, nos termos da configuração agambeniana, aponta a ubiquidade da exceção e seu pertencimento à própria estrutura do poder e da constituição política do Ocidente, não apenas do ponto de vista institucional, mas 
biopolítico. O Estado se apropria, assim, da própria vida, recorrendo à violência para a manutenção de uma suposta ordem. Esse é o retrato do biopoder.

Eis a exigência de uma reflexão sobre a força de lei - vigência sem aplicação e aplicação sem vigência - como formas assumidas pela teoria do estado de exceção de Giorgio Agamben na realidade jurídico-política brasileira no contexto de uma economia globalizada. Trata-se da experiência atual de relativização da soberania e perda relativa do poder dos Estados que traduz o decréscimo de garantia dos direitos que the acompanha. Num espaço neoliberal de um Estado fraco para regular a ordem econômica, mas forte para executar seus interesses, ou mesmo de um Estado que, pretendendo regular tais forças, reverbera numa "captura regulatória", a figura da decisão sobreleva-se como o objeto da disputa política e econômica e, portanto, como inevitável problema jurídico.

A percepção de que vivemos em um estado de exceção decorre de uma leitura da história a contrapelo, que não se contenta em contar a história dos que venceram, mas atende ao apelo obscuro de nossa época. As atuais circunstâncias que invadem os espaços jurídico-políticos no Brasil exigem essa postura, demandando o reconhecimento de que 1964 não chegou ao fim e que a exceção não é uma ruptura com a ordem, mas guarda com ela um relacionamento nada trivial. Torna-se, pois, cada vez mais urgente denunciar a terra de ninguém do estado de exceção.

Por outro lado, aquilo que aqui está colocado como uma crítica radical também pode ser visto como uma leitura a-histórica da civilização ocidental. Ao buscar os traços da biopolítica e da relação de exceção na configuração de todo o poder Ocidental, as suas categorias podem recair seja em recusa ou desconsideração da historicidade das relações de poder, seja em perda de potencial analítico decorrente da baixa capacidade explicativa de uma categoria que ao pretender explicar tudo, explica pouco ou nada. Além disso, as particulares geopolíticas são desconsideradas ao se tomar o poder político do Ocidente como homogêneo. Em resumo, pode-se criticar o universalismo e o caráter a-histórico de uma definição que é capaz de explicar a ontologia de um poder em sociedade em sociedades separadas por séculos ou milênios e/ou sociedades da periferia e do centro do capitalismo.

Para que seja possível confrontar essas objeções, deve-se pontuar que se Agamben afirma que é "impossível derrotar um poder se não compreendermos sua lógica" (AGAMBEN, 2013a), essa lógica não pode se exaurir no mero reconhecimento 
da existência de uma relação de exceção ou de uma anomia. Há uma configuração específica que permite esse desenvolvimento e isso se manifestaria de forma diferente em cada contexto.

Nesse sentido, deve-se destacar que a relação de exceção assume uma particular relevância na realidade brasileira, em cujo território, na condição de colônia, demonstrava o espaço de exceção que vigorava a despeito e como sustento das ditas conquistas civilizacionais europeias. Em outros termos, a realidade da exceção era de todo evidente, já que a colônia constituía o espaço territorial de suspensão do direito da metrópole. O trabalho escravo brasileiro sustentava a liberdade e os direitos defendidos na Europa. A vida e a política europeia incluíam a vida colonial como vida matável. Era muito natural a distinção entre metrópole civilizada e esclarecida portadora de direitos e liberdades e o seu sustento por colônias exploradas e escravizadas.

O campo de concentração é o escárnio dessa lógica esclarecida, pois coloca a realidade da exceção no seio de um sistema constitucional tão progressista como o de Weimar. Talvez a linguagem mais próxima da realidade brasileira seja, inclusive, a desse paradigma colonial, mas se a necessária vinculação territorial. A exceção na realidade brasileira não se esgota no período colonial, mas constitui um importante espaço par vislumbrar com clareza a exceção que atualmente se escancara com a sujeição e subordinação Brasileira aos Estados Unidos, tão claramente e simbólicamente manifestada pela continência que a pessoa que atualmente ocupa a presidência do Brasil prestou à bandeira estadunidense.

Além disso, no que concerne à perspectiva de uma política que vem e de uma comunidade que vem, não se pode ignorar que o filósofo italiano fala a partir do contexto europeu, no qual se presume ter atravessado um período de estabilização do Estado Democrático de Direito e supostamente experimentado o Estado de bemestar social. Esse fato traz diferentes implicações de como poderia se orientar um prognóstico na Europa e de como ele poderia se desenvolver no contexto brasileiro, que sequer passou pela consolidação mínima do modelo liberal. A identificação do lugar do Brasil no capitalismo, a sua condição periférica e de dependência no contexto da divisão internacional do trabalho, aliado à peculiaridade da sua formação histórica não atravessa impunemente a formação e compreensão do direito brasileiro. Nesse sentido, não há como simplesmente pensar uma tarefa política para o Ocidente sem 
considerar a posição periférica do Brasil e sem apontar a configuração do poder e do direito no Brasil.

\section{REFERÊNCIAS}

AGAMBEN, Giorgio. A democracia é um conceito ambíguo: depoimento. Atenas: outubro de 2013a. Entrevista concedida a Anastasia Giamali, para o ALBA, e Dimosthenis PapadatosAnagnostopulos, para a RedNotebook. In: Blog da Boitempo. São Paulo: 4 de julho de 2014. Disponível em: <http://blogdaboitempo.com.br/ 2014/07/04/agamben-a-democracia-e-umconceito-ambiguo/>. Acesso em: mar. 2015.

. Arqueologia da obra de arte. Transliteração e tradução de Vinícius N. Honesko. Princípios Natal, RN, v. 20, n. 34, p. 349-361, jul./dez. 2013b.

. Da Teologia Política à Teologia Econômica. Tradução portuguesa de Selvino José Assmann. Interthesis - Revista Internacional Interdisciplinar, v. 2, n. 2 jul/dez 2005. Entrevista concedida a Gianluca Sacco.

. Entrevista com Giorgio Agamben. Revista do departamento de psicologia - UFF, v.18 -n.1, jan./jun. 2006. Entrevista concedida a Flávia Costa.

. Estado de exceção e genealogia do poder. Trad. Daniel Arruda Nascimento. Revista Brasileira de Estudos Políticos. Belo Horizonte, n. 108, p. 21-39, jan./jun. 2014a.

. Estado de Exceção. São Paulo: Boitempo, 2011a.

. Homo Sacer: O poder soberano e a vida nua I. 2.ed. Belo Horizonte: Editora UFMG, 2010a.

Meios sem fim: notas sobre a política. Trad. Davi Pessoa Carneiro. Belo Horizonte: Autêntica Editora, 2015a. (FILÔ/Agamben)

. O homem sem conteúdo. Tradução de Cláudio Oliveira. $2^{a}$ ed. Belo Horizonte: Autêntica Editora, 2013d. (FILÔ/Agamben;2).

. O que é o contemporâneo e outros ensaios. Tradução de Vinícius Nikastro Honesko. Chapecó, SC: Argos, 2009.

Signatura Rerum: sobre el metodo. Trad. de Flavia Costa y Mercedes Ruviluso. Barcelona: Editorial Anagrama, 2010d.

Stasis: la guerra civile come paradigma politico. Homo Sacer, II, 2. Torino: Bollati Boringhieri, 2015b. 
ARENDT, Hannah. A condição humana. 9.ed. Rio de Janeiro: Forense Universitária, 1999.

ASSMANN, Selvino José; BAZZANELA, Sandro Luiz. A vida como potência a partir de Nietzsche e Agamben. São Paulo: LiberArs, 2013.

Apresentação. in: AGAMBEN, Giorgio. Profanações. Tradução e

apresentação Selvino José Assmann. São Paulo: Boitempo, 2007, páginas 7-14.

BENJAMIN, Walter. Magia e técnica, arte e política. São Paulo: Brasiliense, 2005.

CAVALLETTI, Andrea. A guerra civil paradigma da política. 2015. Disponível em: $<$ http://flanagens.blogspot.com.br/2015/03/a-guerra-civil-paradigma-dapolitica.html.>. Acesso em: dez. 2015.

MECCARELLI, Massimo. Dissenso político e expansão do sistema penal: uma análise comparada sobre os regimes de legalidade na Itália e na França ao fim do século XIX. In: DAL RI JR., Arno; NUNES, Diego (org.). Anais do Encontro de história do direito da UFSC. Florianópolis: Fundação Boiteux, 2009.

ROMANO, Santi. O Ordenamento Jurídico. Florianópolis: Fundação Boiteux, 2008.

SCHMITT, Carl. Teologia Política: Quatro capítulos sobre a doutrina da soberania. Trad. Inês Lohbauer. São Paulo: Scritta, 1996. Parte 2, p. 81-133. In: A crise da democracia Parlamentar. 130 p. (Clássica).

Artigo recebido em: 24/10/2019

Artigo aprovado em: 11/12/2019

Artigo publicado em: 08/01/2020 